Distributive Justice Beliefs and Group Idea Generation:

Does a Belief in Equity Facilitate Productivity?

\author{
Jack A. Goncalo ${ }^{1}$ \\ Cornell University
}

Sharon H. Kim

Cornell University

IN PRESS, JESP

\footnotetext{
${ }^{1}$ Authors' Note: We thank Maura Belliveau, Ya-Ru Chen, Edward Lawler, Laurie Weingart and seminar participants at Emory University and Carnegie-Mellon University for the helpful feedback during the preparation of this article. We also thank Jim Sherman and the two anonymous reviewers for their constructive comments. Please address correspondence concerning this article to Jack Goncalo, School of Industrial and Labor Relations, Cornell University, Ithaca, NY 14853; e-mail: jag97@cornell.edu.
} 


\title{
Distributive Justice Beliefs and Group Idea Generation: Does a Belief in Equity Facilitate Productivity?
}

\begin{abstract}
The equity rule is favored by groups that emphasize productivity, but there is limited support for the notion that equity actually facilitates productivity in groups (Deutsch, 1985). We propose that the relationship between equity and productivity may depend on whether individual group members have an independent or interdependent self-construal. This prediction was tested in an experiment in which groups endorsed either an equity rule or an equality rule for distributing resources and then generated ideas as a group. The results showed that equity facilitated productivity (e.g., the number of ideas generated) but only in groups whose members had been primed with an independent self-construal. The results of both self-report and video-tape data support competition as the mechanism that explains this productivity gain. This work contributes to research on both distributive justice and small group performance by specifying more clearly the conditions under which a belief in equity will stimulate productivity.
\end{abstract}

Keywords: Distributive justice; equity-equality; group idea generation 


\section{Distributive Justice Beliefs and Group Idea Generation: Does a Belief in Equity Facilitate Productivity?}

Distributive justice addresses the distribution of socially-valued goods and resources (Foa $\&$ Foa, 1974) and the perceived fairness of the outcomes that one receives (Frohlich, 2007). There are many rules that people may use to allocate these social goods and resources (Deutsch, 1985), but two in particular have received a great deal of attention: The equity rule, in which people are rewarded in direct proportion to their individual contribution (Adams, 1963; 1965), and the equality rule, in which all members of the group receive the same share regardless of their individual contribution (Deutsch, 1975).

Equity and equality each represent strongly held beliefs about the fairest way to distribute resources, but some groups may emphasize the value or legitimacy of one rule over the other (Mannix, Neale \& Northcraft, 1995). The equity rule is consistently favored by groups that emphasize productivity (Leventhal, 1976; Leung \& Park, 1986). However, in a series of experiments, Deutsch (1985) found that although participants' expected their own productivity to be higher under the equity rule, their actual performance was not significantly higher relative to the participants who followed an equality rule. These findings suggest that the belief in the equity-productivity relationship may be illusory; yet another lay prediction about groups unsubstantiated by the data (Stroebe, Diehl \& Abakoumkin, 1992). In contrast, we propose that the equity rule may indeed promote productivity in groups, but that in order to produce such an effect, there must be congruence between the allocation rule and the dominant psychological orientation of the individual group members.

Equity-equality rules and productivity in idea generating groups 
In research on distributive justice it has been theorized that equity should facilitate productivity by highlighting disparities among individuals' levels of performance and thereby motivating group members to compete for a larger share of the reward (Deutsch, 1985; Chen \& Church, 1993). Indeed, there is strong evidence that competition does facilitate productivity, particularly in brainstorming tasks, in which the goal is to generate as many ideas as possible (Osborn, 1957; Simonton, 1999). For instance, competition has been shown to facilitate idea generation in both electronic and face-to-face groups by motivating individuals to match their performance with a more productive member of the group (Paulus, Larey, Putman, Leggett \& Roland, 1996; Munkes \& Diehl, 2003; Dugosh \& Paulus, 2005). In addition, research on social motives suggests that a pro-self orientation in groups (e.g. the motive to compete) leads to better performance on creative idea generation tasks (Beersma \& De Dreu, 2005; De Dreu, Nijstad \& van Knippenberg, 2008).

Yet, the lack of support for the equity-productivity relationship suggests that equity alone may not automatically lead to a competitive orientation (Deutsch, 1985). The extent to which equity triggers competition may depend on individual group members' self-construal, or how they view themselves in relationship to others (Singelis, 1994). People with an independent selfconstrual view themselves as unique and separate from the group while people with an interdependent self-construal view themselves as more connected to and less differentiated from others (Markus \& Kitayama, 1991; Stapel \& Koomen, 2001). An interdependent self may not be as motivated by an equity rule since they do not seek opportunities to stand out but rather prefer to blend-in and to maintain harmony with other group members (Markus \& Kitayama, 1991). In contrast, an independent self might be more motivated to compete since the equity rule allows them the opportunity to stand out by expressing more ideas than others (Triandis \& Gelfand, 
1998). Therefore, in a group composed of individuals with an independent self-construal, a salient equity rule may activate the motive to compete, and that competitive orientation should, in turn, facilitate the expression of ideas.

In sum, the current research investigates how the endorsement of equity (as opposed to equality) influences the expression of ideas in face-to-face groups. In the experiment that follows, we test the hypothesis that productivity will be highest in groups (a) that collectively endorse the equity rule for distributing resources and (b) whose members have been primed with an independent self-construal.

\section{Method}

\section{Participants and design}

Participants were 216 undergraduates from a large private university in the United States (39\% men, $61 \%$ women, mean age of 21 years) who were paid $\$ 15$ in exchange for their participation. Preliminary analyses revealed no significant differences in predicted effects by the sex composition of the group. This measure was not directly related to this article, and no further mention of it will be made. The experiment had a 2 (self-construal: independent versus interdependent) x 2 (reward allocation: equity versus equality) between-groups design. Participants were randomly assigned to groups of three resulting in a total of 72 groups.

\section{Experimental procedure}

Self-construal manipulation: Upon entering the experiment, participants were told that they would first work as individuals on a task that was ostensibly intended to improve their task focus. Self-construal was manipulated by asking participants to complete a pronoun circling task (e.g. "I" versus "We") that has been shown to successfully shift self-construals in previous research (see Brewer \& Gardner, 1996 for a detailed description). 
Equity-equality manipulation: After the first task was completed, participants were asked to, as a group, read a scenario about a team that was awarded a fixed bonus for successfully completing a project but in the scenario some members of the team had contributed more than others. Each group was given 5 minutes to discuss the issue as a group and list arguments to support the decision to divide the bonus equally so that each member of the team received the same bonus (equality) or to divide the bonus unequally to give some members of the team a higher bonus than others (equity).

\section{Dependent measures}

Productivity: After the reward allocation discussion, productivity was measured using a group brainstorming task. Each group was given 10 minutes to generate ideas about new businesses that could replace an empty space left vacant by a mismanaged restaurant. Groups were instructed to generate as many ideas as possible. No further instructions were given. Productivity was measured by counting the number of non-redundant ideas generated by each group.

Competitive orientation: After the experiment, participants completed a survey in which they were asked to imagine how they would behave in a series of eight hypothetical social situations that were developed to assess the extent to which people view themselves as competitive toward others (Triandis, Chen \& Chan, 1998). After each of the eight scenarios, participants were presented with four options, of which one specific option corresponded to competition. A sample scenario is, "Suppose you had to use one word to describe yourself, which one would you use?: (a) competitive, (b) cooperative (c) unique, (d) dependable." Participants were asked to check the one option that best reflected how they would behave in the situation described. All participants answered the 8 questions as instructed. We then counted 
the number of options checked that corresponded to competition and aggregated the individual scores to the group level by calculating the mean for each group. A significant intra-class correlation demonstrated sufficient within-group agreement to justify aggregation to the group level, ICC $=.71, \mathrm{p}<.01$ (Bliese, 2000). To ease the interpretation of our results, we divided the total number of competitive responses by eight to get the percentage of responses that fell into that category.

Competitive behavior: We also videotaped each group's brainstorming session and coded for competitive behavior during the interaction. More specifically, a single coder counted the number of times one individual interrupted another individual while he/she was expressing an idea, assuming that competitive individuals would show less regard for the ideas suggested by other group members (and tend to break into another person's turn). A second coder watched $25 \%$ of the video tapes to establish reliability $(\mathrm{ICC}=.68, \mathrm{p}<.01)$. Due to a malfunction with the video equipment, the brainstorming sessions of two groups could not be coded.

Manipulation checks: A free-response task was employed as the manipulation check for the self-construal prime (Kuhn \& McPartland, 1954). Participants provided self-descriptions by finishing the prompt "I am [blank]." Responses were then coded on a 1 to 5 Likert scale with 1 being "completely independent" and 5 being "completely interdependent" by two coders who worked independently and were unaware of the study's hypotheses. Agreement between the two coders was acceptable $(\mathrm{ICC}=.76, \mathrm{p}<.01)$ so their scores were averaged together. A significant intra-class correlation demonstrated sufficient within-group agreement to justify aggregation to the group level, $\mathrm{ICC}=.58, \mathrm{p}<.01($ Bliese, 2000).

Our manipulation of equity versus equality was checked with a 4-item scale. Participants responded to items on a 5-point Likert scale with 1 being "strongly agree" and 5 being "strongly 
disagree." Two sample items are: "People who contribute more to the group should always get a larger share of the reward" and "Members of a group should be given equal rewards regardless of their contributions to the group" (reverse-scored). The scale was reliable $(\alpha=.82)$ and therefore answers to the four items were averaged together. A significant intra-class correlation demonstrated sufficient within-group agreement to justify aggregation to the group level, ICC $=.71, \mathrm{p}<.01($ Bliese, 2000$)$.

\section{Results}

\section{Manipulation checks}

A 2 (self-construal: independent versus interdependent) x 2 (reward allocation: equity versus equality) ANOVA on ratings of participants" "I am" statements verified a significant main effect of self-construal, $\mathrm{F}(1,68)=4.05, \mathrm{p}<.05$, such that participants assigned to the "I" condition described themselves as being significantly more independent $(\mathrm{x}=2.38 ; \mathrm{SD}=.23)$ than did participants in the "We" condition $(x=2.51 ; \mathrm{SD}=.29)$. There was no significant main effect of reward allocation, $\mathrm{F}<1$, ns, nor was there a significant interaction, $\mathrm{F}<1$, ns.

A 2 (self-construal: independent versus interdependent) x 2 (reward allocation: equity versus equality) ANOVA on groups' responses to the equity-equality items revealed a significant main effect of reward allocation, $F(1,68)=9.06, p<.01$, such that participants in the equity condition endorsed equity $(\mathrm{x}=2.56 ; \mathrm{SD}=.58)$ more strongly than did participants in the equality condition $(\mathrm{x}=2.96 ; \mathrm{SD}=.57)$. There was no significant main effect of self-construal, $\mathrm{F}<1$, $\mathrm{ns}$, nor was there a significant interaction, $\mathrm{F}(1,68)=1.34$, ns.

\section{Intra-group competition}

There was a marginally significant main effect of self-construal such that groups in the " $\mathrm{I}$ " condition reported being slightly more competitive $(\mathrm{x}=25.71 \%, \mathrm{SD}=7.92 \%)$ than $\operatorname{did}$ 
groups in the "We" condition, $(\mathrm{x}=22.52 \% ; \mathrm{SD}=8.36 \%), \mathrm{F}(1,68)=3.17, \mathrm{p}<.10$. There was no significant main effect of reward allocation, $\mathrm{F}<1$, ns. There was a significant interaction, $\mathrm{F}$ $(1,68)=9.30, \mathrm{p}<.01$, such that groups in the "I" condition reported being more competitive when the group endorsed equity $(x=29.41 \%, \mathrm{SD}=7.14 \%)$ than when the group endorsed equality $(\mathrm{x}=22.22 \% ; \mathrm{SD}=7.15 \%), \mathrm{F}(1,33)=8.86, \mathrm{p}<.01$. Furthermore, groups who endorsed equity were significantly more competitive in the " $\mathrm{I}$ " condition $(\mathrm{x}=29.41 \%$; $\mathrm{SD}=$ $7.14 \%)$ than in the "We" condition $(x=20.61 \% ; \mathrm{SD}=7.54 \%), \mathrm{F}(1,33)=12.85, \mathrm{p}<01$.

The video-tape measure of competition yielded a similar pattern. There was no significant main effect of self-construal, $F(1,66)=2.70, \mathrm{~ns}$, and no significant main effect of reward allocation, $\mathrm{F}(1,66)=1.04, \mathrm{~ns}$. There was a significant interaction, $\mathrm{F}(1,66)=4.37, \mathrm{p}$ $<.05$, such that groups in the "I" condition were more competitive when the group endorsed equity $(\mathrm{x}=2.94, \mathrm{SD}=1.85)$ than when the group endorsed equality $(\mathrm{x}=1.65 ; \mathrm{SD}=1.69), \mathrm{F}(1$, $32)=4.52, p<.05$. Additionally, groups who endorsed equity were significantly more competitive in the " $\mathrm{I}$ " condition $(\mathrm{x}=2.94 ; \mathrm{SD}=1.85)$ than in the "We" condition $(\mathrm{x}=1.39 ; \mathrm{SD}$ $=1.72), \mathrm{F}(1,32)=6.61, \mathrm{p}<.05$.

\section{Group productivity}

We performed a 2 (self-construal: independent versus interdependent) x 2 (reward allocation: equity versus equality) between-groups ANOVA on the sheer number of ideas generated. There was no main effect of self-construal, $\mathrm{F}(1,68)=1.13$, ns, and no main effect of equity-equality rule, $\mathrm{F}<1$, ns; however, there was a significant interaction, $\mathrm{F}(1,68)=4.34$, $\mathrm{p}$ $<.05$. As predicted, groups that emphasized equity generated significantly more ideas in the "I" condition $(\mathrm{x}=53.24, \mathrm{SD}=16.63)$ than in the "We" condition $(\mathrm{x}=40.58, \mathrm{SD}=19.79), \mathrm{F}(1,34)$ $=4.26, \mathrm{p}<.05$. Also, as expected, groups in the "I" condition generated significantly more ideas 
when they endorsed equity $(\mathrm{x}=53.24, \mathrm{SD}=16.63)$ than when they endorsed equality $(\mathrm{x}=41.00$, $\mathrm{SD}=16.53), \mathrm{F}(1,33)=4.76, \mathrm{p}<.05($ See Figure 1$)$. Thus, groups whose members had been primed with the independent self-construal and endorsed the equity rule were more productive and reported more competitive social motives than did groups in the other three conditions. A mediational analysis (Baron \& Kenny, 1986) further supported the hypothesis that competition (measured both as a self-reported competitive orientation and as competitive behavior) was the psychological mechanism explaining the productivity gain in the "I/Equity" condition relative to the other three conditions (See Figures $2 \mathrm{a} \& 2 \mathrm{~b}$ ).

\section{Discussion}

There is limited support for the notion that equity will facilitate productivity in groups even though many believe in the veracity of this relationship (Deutsch, 1985). Our results suggest that the purported relationship between equity and productivity may only emerge in groups whose members have an independent self-construal. The results cannot be explained by the anticipation of being directly rewarded for suggesting new ideas since we manipulated groups' beliefs about how rewards should be distributed apart from the prospect of actually receiving payment (Toubias, 2006). An advantage of this approach is that we separated distributive justice beliefs from the provision of external rewards that could raise extrinsic task motivation (Lepper, Greene \& Nisbett, 1973) and stifle creative problem solving (e.g. Amabile, 1979). The results suggest it may be possible to facilitate idea generation, not only by rewarding people directly, but also by making distributive justice beliefs salient prior to working on a group task.

The results supported competition as the psychological mechanism underlying the productivity gain; however, there may be other important mediating variables. For instance, it is 
possible that an interdependent self may experience less regulatory fit while discussing equity than equality (Higgins, 2006) which may, in turn, reduce task engagement and performance (Forster, Higgins \& Idson, 1998). Nevertheless, the results of this study suggest that it may be worth re-opening the equity-productivity question. The simple prediction that equity facilitates productivity might be replaced with a more complex series of research questions that take into account the contextual factors that combine with equity to promote competition and group ideation. 


\section{References}

Adams, J. S. 1963. Toward an understanding of inequity. Journal of Abnormal and Social Psychology, 67: 422-436.

Adams, J. S. 1965. Inequity in social exchange. In L. Berkowitz (Ed.), Advances in experimental social psychology, vol. 2: 267-299. New York: Academic Press.

Amabile, T.M. (1979). The effects of external evaluation on artistic creativity. Journal of Personality and Social Psychology, 37, 2, 221-233.

Baron, R. M., \& Kenny, D. A. (1986). The moderator-mediator variable distinction in social psychological research: Conceptual, strategic, and statistical considerations. Journal of Personality and Social Psychology, 51, 1173-1182.

Beersma, B., \& De Dreu, C.K.W. (2005). Conflict's consequences: Effects of social motives on Post-negotiation creative and convergent group functioning and performance. Journal of Personality and Social Psychology, 89, 358-374

Bliese, P. D. (2000). Within-group agreement, non-independence, and reliability: Implications for data aggregation and analyses. In K. J. Klein and S. W. J. Kozlowski (Eds.), Multilevel theory, research, and methods in organizations: Foundations, extensions, and new directions, pp. 349-381. San Francisco, CA: Jossey-Bass.

Brewer, M.B., \& Gardner, W. (1996). Who is this "we"? Levels of collective identity and self representations. Journal of Personality and Social Psychology, 71, 83-93.

Chen, Y. \& Church, A.H. (1993). Reward allocation preferences in groups and organizations. The International Journal of Conflict Management, 4, 1, 25-59. 
De Dreu, C. K. W., Nijstad, B. A., \& Van knippenberg, D. (2008). Motivated information processing in group judgment and decision making. Personality and Social Psychology Review, 12, 22-49.

Deutsch, M. (1975). Equity, equality and need: What determines which value will be used as the basis of distributive justice. Journal of Social Issues, 31, 137-149.

Deutsch, M. (1985). Distributive justice, a social psychological perspective. New Haven: Yale University Press.

Dugosh, K.L. and Paulus, P.B., (2005). Cognitive and social comparison processes in brainstorming. Journal of Experimental Social Psychology, 41, 313-320.

Foa, U.G. \& Foa, E.B. (1974). Societal studies of the mind. Springfield, IL: Charles C. Thomas. Forster, J., Higgins, E.T., \& Idson, L.C. (1998). Approach and avoidance strength during goal attainment: Regulatory focus and the "goal looms larger" effect. Journal of Personality \&Social Psychology, 75, 1115-1131.

Frohlich, N. 2007. A very short history of distributive justice. Social Justice Research, 20: 250262.

Higgins, E. T. (2006). Value from hedonic experience and engagement. Psychological Review,113, 439-460.

Kuhn, M.H., \& McPartland, T. (1954). An empirical investigation of self-attitudes. American Sociological Review, 19, 69-76.

Lepper, M.R., Greene, D. \& Nisbett, R.E. (1979). Undermining children's intrinsic interest with extrinsic rewards: A test of the "over-justification" hypothesis. Journal of Personality and Social Psychology, 28, 129-137. 
Leung, K. \& Park, H. (1986). Effects of interactional goal on choice of allocation rule: A crossnational study. Organizational Behavior and Human Decision Processes, 37, 1, 111-120.

Leventhal, G. S. 1976. Fairness in social relationships. In J. W. Thibaut, J. T. Spence, \& R. C. Carson (Eds.), Contemporary topics in social psychology: 211-240. Morristown, NJ: General Learning Press.

Mannix, E.A., Neale, M.A., \& Northcraft, G.B. (1995). Equity, equality, or need? The effects of organizational culture on the allocation of benefits and burdens. Organizational Behavioral and Human Decision Processes, 63, 276-286.

Markus, H.R., \& Kitayama, S. (1991). Culture and the self: Implications for cognition, emotion, and motivation. Psychological Review, 98, 224-253.

Munkes, J., \& Diehl, M. (2003). Matching or competition? Performance comparison processes in an idea generation task. Group Processes and Intergroup Relations, 6, $305-320$.

Osborn, A.F. (1957). Applied Imagination. New York: Scribner.

Paulus, P. B., Larey, T. S., Putman, V. L., Leggett, K. L., \& Roland, E. J. (1996). Social influence process in computer brainstorming. Basic and Applied Social Psychology, 18, $3-14$.

Simonton, D. K. (1999). Creativity as blind variation and selective retention: Is the creative process Darwinian? Psychological Inquiry, 10, 309-328.

Singelis, T.M. (1994). The measurement of independent and interdependent self-construals. Personality and Social Psychology Bulletin, 20, 5, 580-591.

Stapel, D.A. \& Koomen, W. (2001). I, We, and the effects of others on me: How self-construal level moderates social comparison effects. Journal of Personality and Social Psychology, $5,766,781$. 
Stroebe, W., Diehl, M. \& Abakoumkin, G. (1992). The illusion of group effectivity. Personality and Social Psychology Bulletin, 18, 5, 643-650.

Toubias, O. (2006). Idea generation, creativity and incentives. Marketing Science, 25, 5, 411-425.

Triandis, H.C., Chen, X.P., \& Chan, D.K. (1998). Scenarios for the measurement of collectivism and individualism. Journal of Cross-Cultural Psychology, 29, 275-289

Triandis, H.C., \& Gelfand, M.J. (1998). Converging measurement of horizontal and vertical individualism and collectivism. Journal of Personality and Social Psychology, 74, 118128. 


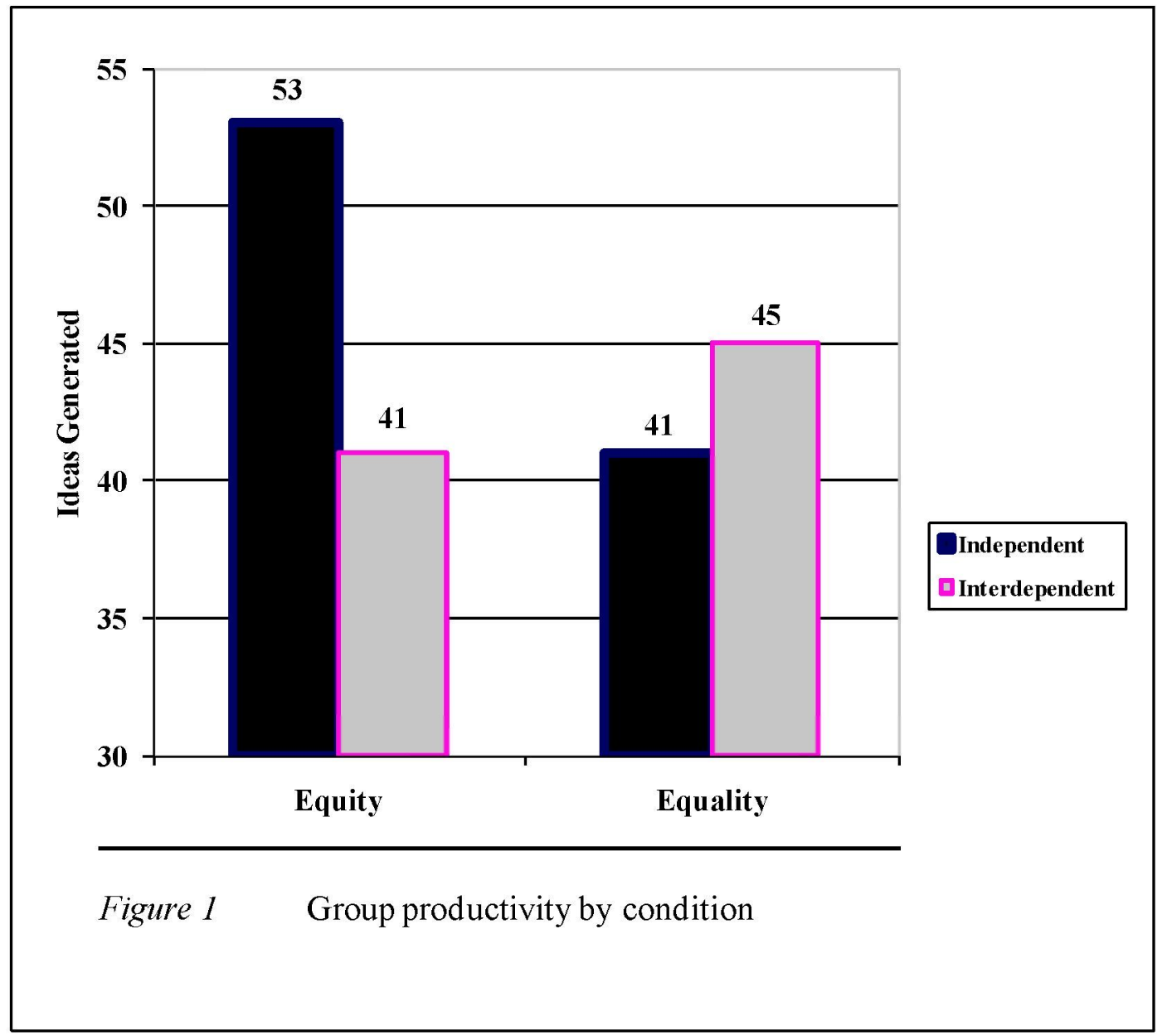




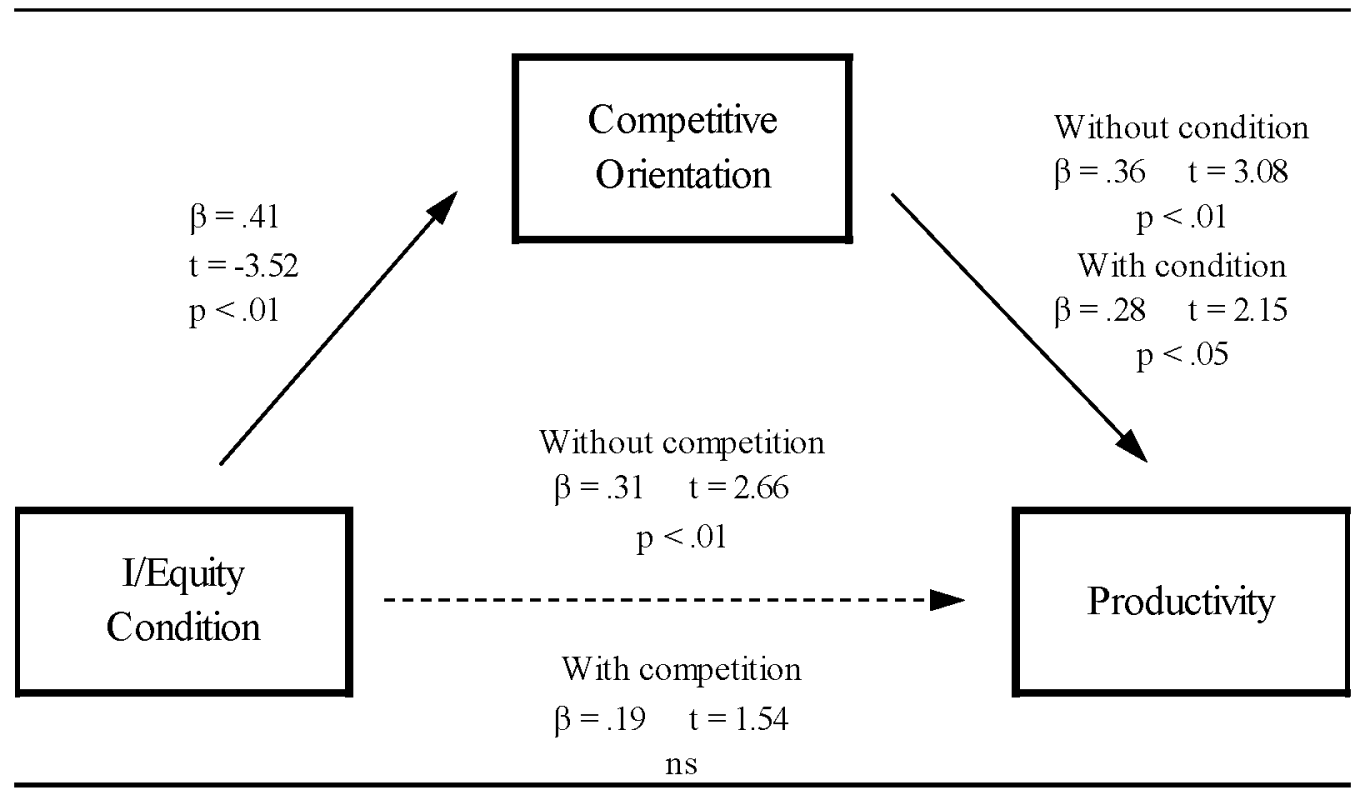

Figure $2 a$

Main and mediating effects of condition, competitive orientation (self-report data) and productivity. Dotted arrow indicates that a relationship fell below significance in the full model (e.g. that there is full mediation). $\mathrm{Z}=1.90, \mathrm{p}<.05$

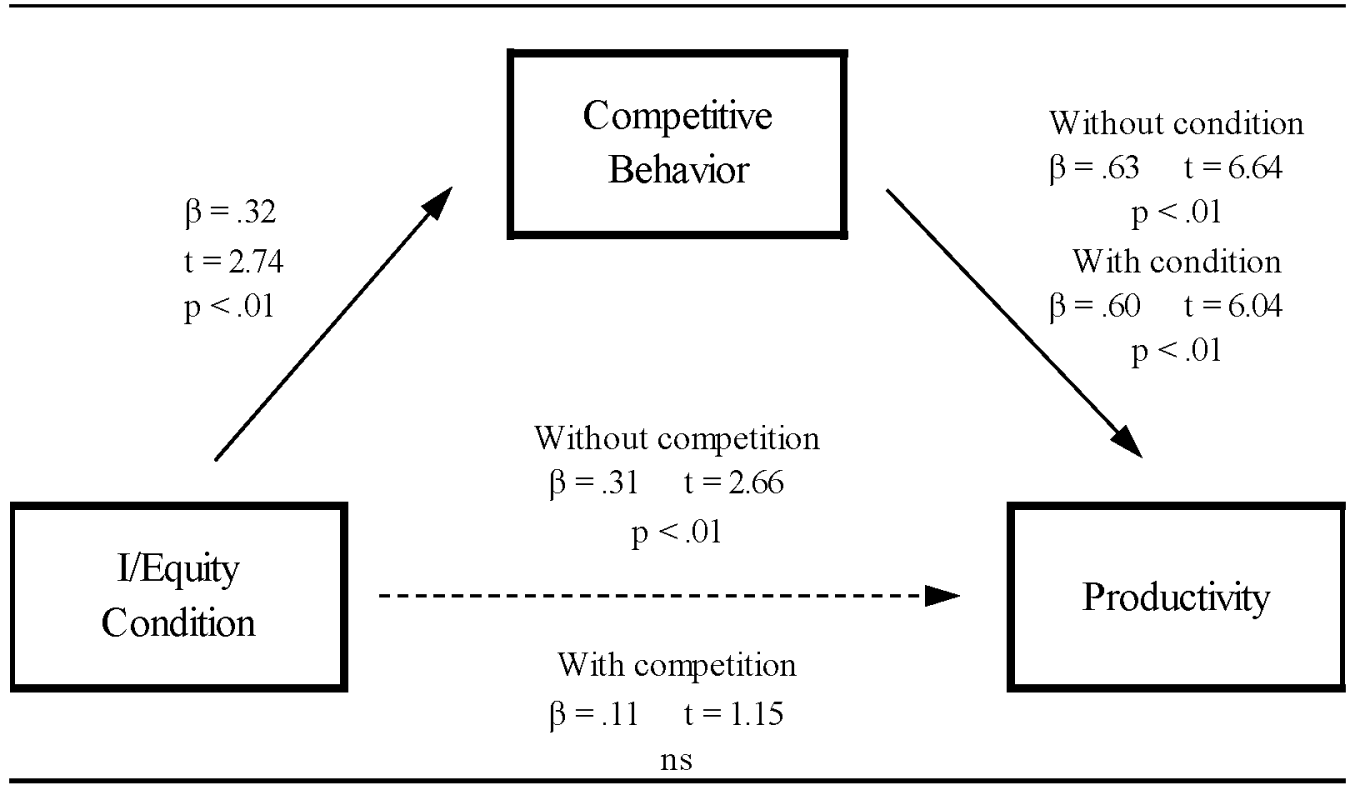

Figure $2 b$

Main and mediating effects of condition, competitive behavior (video-tape data) and productivity. Dotted arrow indicates that a relationship fell below significance in the full model (e.g. that there is full mediation). $Z=2.50, p<.01$ 